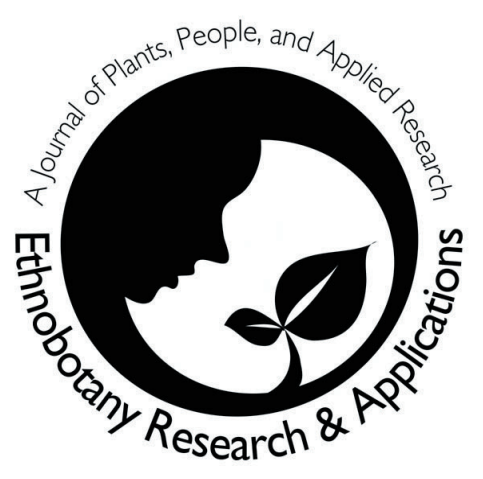

\title{
Crops and Cultures in the Pacific: New Data and New Techniques for the Investigation of Old Questions
}

\author{
Barbara Pickersgill
}

\begin{abstract}
Fifty years ago Carl Sauer suggested, controversially and on the basis of theory rather than evidence, that Southeast Asia was the source area for agriculture throughout the Old World, including the Pacific. Since then, the archaeobotanical record (macroscopic and microscopic) from the Pacific islands has increased, leading to suggestions, also still controversial, that Melanesia was a center of origin of agriculture independent of South-east Asia, based on tree fruits and nuts and vegetatively propagated starchy staples. Such crops generally lack morphological markers of domestication, so exploitation, cultivation and domestication cannot easily be distinguished in the archaeological record. Molecular studies involving techniques such as chromosome painting, DNA fingerprinting and DNA sequencing, can potentially complement the archaeological record by suggesting where species which were spread through the Pacific by man originated and by what routes they attained their present distributions. A combination of archaeobotanical and molecular studies should therefore eventually enable the rival claims of Melanesia versus South-east Asia as independent centers of invention of agriculture to be assessed.
\end{abstract}

\section{Introduction}

50 years ago, the American geographer Carl Sauer published an influential synthesis of his ideas on agricultural origins and dispersals (Sauer, 1952). He argued that plant cultivation began in wooded areas, because forest is easier to clear than grassland, among sedentary people such as fishermen, who already had a secure form of subsistence. More species, hence more potential domesticates, are found in areas of topographic and climatic diversity, so Sauer suggested that agriculture first developed in a mountainous region with a monsoon climate. South-east Asia seemed to him the region which best satisfied all these requirements. Sauer therefore concluded that all agriculture outside the Americas was derived from a single "hearth," located in the part of South-east Asia now known as the Golden Triangle and notorious for production of plants for purposes other than food. Vegetatively propagated crops, such as bananas, yams, sugar cane and taro, were and still are important in South-east Asia, and Sauer argued that these were domesticated earlier than seed-propagated crops.

One of the more critical reviewers of Sauer's book was Paul Mangelsdorf (1953), who dominated the field of maize evolution for over two decades. Mangelsdorf considered that if Sauer had consciously set out to devise an untestable hypothesis, he could hardly have bettered the one outlined in his book. At the time of Mangelsdorf's review, archaeobotanical materials, especially soft starchy storage organs and fruits, were thought unlikely to survive in the wet tropics. Without an archaeobotanical record, the age of the South-east Asian complex of domesticates could not be compared with the radiocarbon-dated remains of seed crops from sites in South-west Asia and Mexico. Morphological markers of domestication are often less obvious in crops grown for their vegetative parts than in seed crops, making it difficult to distinguish exploita-

\section{Correspondence}

Barbara Pickergill, Dept. of Agricultural Botany, School of Plant Sciences, The University of Reading, Whiteknights, PO Box 221, Reading RG6 6AS, UNITED KINGDOM

b.pickersgill@reading.ac.uk

Ethnobotany Research \& Applications 2: 1-8 (2004) 
Ethnobotany Research \& Applications

tion of wild plants from domestication of cultivated plants. In annual seed crops, experimentally produced hybrids can provide information on relationships between cultigens and their possible wild progenitors, hence on possible centers of domestication. But such studies are much less feasible in perennials which may take years to reach reproductive maturity, or in which all or much of the capacity for sexual reproduction has been lost, as in many bananas, yams, sugar cane and kava.

In northern Europe, analyses of pollen and charcoal in cores taken from lakes and bogs have provided strong, albeit indirect, evidence for the arrival of cereal agriculture. But vegetatively propagated crops, which may flower only rarely and which, unlike grasses, are not generally wind-pollinated, do not contribute significantly to the general pollen rain. It seemed unlikely that small-scale slashand-burn clearances of forest for shifting cultivation would produce decreases in tree pollen or increases in charcoal detectable in cores taken at a distance from the cleared areas. The pollen record, like the macroscopic remains, thus appeared likely to contribute little to our understanding of agricultural origins in the humid tropics.

Since 1952, advances have been made in archaeology and botany that would have been unimaginable to Sauer or Mangelsdorf. Macroscopic archaeobotanical remains have been recovered from a number of sites in South-east Asia and the Pacific. Microscopic remains such as phytoliths and starch grains have also been recovered and may provide a record for some of the readily-decomposable starchy staples absent from the macroscopic record. Evidence of forest clearance and pollen of some animalpollinated crops have been detected in cores taken for pollen analysis on some Pacific islands. Genetic relationships between crops and their putative wild progenitors can be assessed by various molecular techniques, without the need to synthesize and study hybrids. Some of these techniques can be used to infer the history of colonizations and dispersals in wild or cultivated species. This therefore seems an appropriate time to review the use, and/or the potential, of these data in investigating when and by what route(s) crops or crop complexes diffused through the Pacific region and hence testing Sauer's "untestable" hypothesis.

\section{Macroscopic achaeobotanical remains}

In the Pacific region, archaeobotanical remains have been recovered from dry rock shelters (Hather and Kirch, 1991; Bayliss-Smith, 1996) and from waterlogged sites (Kirch, 1989; Matthews and Gosden, 1997). As in other parts of the world, the time range and the geographic distribution of the sites producing these remains are limited, and some plants are more likely to feature in the macroscopic record than others. Hard endocarps of coconut, Canarium and Pandanus are present, sometimes in quantity, in geographically widely separated sites. Fragments of pods of Inocarpus and seeds of Pometia are also not uncommon (Kirch, 1989; Yen, 1995; Matthews and Gosden, 1997). However, there is as yet no macroscopic record of those staples of present-day indigenous Melanesian agriculture; the aroids (especially taro, Colocasia esculenta) and yams (Dioscorea spp.).

Because there are so many geographical, chronological and taxonomic gaps, the archaeobotanical record has been interpreted very differently by different authors. Yen (1995) argued that western Melanesia was an independent center of agricultural origin, from which Oceanic agricultural systems based on root and tree crops were derived. On the other hand, Spriggs (1996) considered that Melanesia was not a center of agricultural development, although prehistoric Melanesian hunter-gatherers may have had a long tradition of transplanting useful species within and between islands. Bellwood (1996) stated that agriculture reached Melanesia via people of the Lapita culture who, in his opinion, had originated from Taiwan and originally cultivated rice. Bellwood considered that dispersal of tree crops throughout Melanesia and on to islands further east occurred only after $3500 \mathrm{bp}$, associated with spread of the Lapita.

Much of the argument turns on whether the still scanty pre-Lapita remains of various tree fruits and nuts represent wild plants or not. Gosden (1992) considered Canarium indicum from 14,000 BP from the Sepik lowlands of Papua New Guinea site to be domesticated, apparently on the basis of fruit size. However, the range of endocarp dimensions in wild $C$. indicum (or its progenitor) was not given, possibly because, as Matthews and Gosden (1997) point out, Canarium is dispersed by flying foxes and fruit pigeons, both of which are quite capable of moving seeds from planted trees back into the wild and vice versa, making it difficult to identify truly wild populations. Canarium has also been recovered from late Pleistocene sites in Manus and the Solomon Islands (Yen, 1995) and Spriggs (1996) stated that Canarium was transplanted from New Guinea to New Ireland and Buka Island at the beginning of the Holocene, though he gave no reason for discounting natural long-distance dispersal. Even in Lapita sites, where C. indicum is abundantly represented (Kirch, 1989; Matthews and Gosden, 1997), it is not possible to distinguish between exploitation, cultivation and domestication. We therefore cannot yet determine when or where human manipulation of Canarium may have started.

Other plants represented in pre-Lapita remains include coconut, Pandanus, Pometia and other tree products from c. $5800 \mathrm{BP}$, again from the Sepik lowlands (cited in Matthews and Gosden, 1997). However, the most abundant material again comes from Lapita sites (e.g. Kirch, 1989; 


\section{Pickersgill - Crops and Cultures in the Pacific: New Data and New Techniques for the Investigation of Old Questions}

Matthews and Gosden, 1997) and includes coconut endocarps from c. $1200 \mathrm{BC}$. These are reported to be similar in size to those of modern niu vai cultivars, suggesting that the Lapita coconuts had been influenced by human selection (Kirch, 1989), though whether by the Lapita or by earlier cultures cannot as yet be determined (see also Harries et al., this volume).

It has therefore now been demonstrated that macroscopic archaeobotanical remains can be recovered from climates in which Mangelsdorf (1953) thought it impossible that they would survive. However, the gaps in the archaeobotanical record are such that it shows only that the "untestable hypothesis" put forward by Sauer (1952) should eventually be testable.

\section{Microscopic archaeobotanical remains}

Microscopic archaeobotanical remains may be recovered from plant species or from contexts where preservation of macroscopic remains is unlikely, hence may provide a useful complement to the macroscopic record.

Contrary to some pessimistic early expectations, the pollen record does provide datable evidence for prehistoric burning and presumably clearance of forests on various islands of the western Pacific, though in most cases the reasons for these clearances are not clear. Bayliss-Smith (1996) cautions that studies in Australia show that huntergatherers can have substantial impacts on forests, so that evidence of deforestation in highland New Guinea commencing around 10,000 years ago should not be taken as unambiguous evidence for agriculture. Spread of the Lapita culture through the western Pacific around 3500 bp was associated with changes in the pollen record from forest to more open vegetation. At the same time, carbonized particles appeared in the cores, suggesting that the forests were burned, and amounts of clay increased, suggesting that removal of the forest cover led to erosion (Spriggs, 1996). This, together with abundant remains of fruits and nuts, plus scrapers and peelers that could have been used to process taro and/or yams, found by Kirch (1989) in a Lapita site in Melanesia, strongly suggests that forests were cleared to make way for more useful species.

Perhaps the most remarkable pollen record is from Kosrae, in the Eastern Caroline Islands in Micronesia. Abundant pollen of the aroid Cyrtosperma (still grown to a limited extent for its starchy corms, but an insect-pollinated plant which one would not expect to show up in the pollen record) was found in cores from wetland areas, away from known archaeological deposits. Cyrtosperma pollen appeared at levels corresponding to the period of earliest human settlement of the island (around 2000-1700 BP; Athens et al., 1996). Colocasia, breadfruit and coconut pollen appeared slightly later (1523-1350 BP). Abundant pollen of Metroxylon (the genus to which sago palm belongs) was found from zones preceding man's arrival on the island, but soon after man arrived, Metroxylon started to decline, and has now disappeared from Kosrae. Charcoal was absent from the early levels, increased suddenly around 1550-1350 BP, then disappeared equally suddenly. Athens et al. (1996) interpreted these data as evidence of deliberate and rapid destruction of the native forest by the earliest settlers, so that they could plant imported trees and root crops.

The pollen record, taken as a whole, provides convincing evidence that the Lapita were cultivating plants, but not that Lapita agriculture originated in Melanesia rather than further west. More information is needed on the places of origin of the species that the Lapita are assumed to have transported and introduced.

Phytoliths are inclusions of silica within cells of some plants, notably but not exclusively grasses. Like pollen grains, they are resistant to decay. Phytoliths contain sufficient carbon, occluded within the phytolith itself, hence protected from contamination, that samples of phytoliths can be radiocarbon-dated (Kelly et al., 1991). However, individual phytoliths cannot be dated and dates from samples must be treated with caution because phytoliths can be moved upwards or downwards in soils by disturbance or leaching, and decaying roots of contemporary plants may deposit recent phytoliths among phytoliths representing earlier vegetation. Identification also requires care, since one plant often produces phytoliths of several morphological types, from cells in different tissues and/or different parts of the plant (e.g. Hayward and Parry, 1980). Phytoliths often cannot be identified to species, only to genus or family, and their morphology cannot, at least as yet, be used to discriminate between wild versus domesticated forms of a crop species. Thus, rice phytoliths from 7-8000 years ago in a valley in Thailand (Kealhofer and Piperno, 1994) and Musa phytoliths from the earliest levels of the Kuk site in highland New Guinea (cited in Yen, 1995) do not necessarily indicate cultivation of rice or banana, since wild relatives of these two crops still occur in the respective areas

Starch grains have, like pollen but perhaps more surprisingly, proved resistant to decay. Barton et al. (1998) examined a sample of artefacts from an open site in Papua New Guinea and found starch grains on all, whether they had been used or not. However, starch grains on unused artefacts were present in very low frequencies, comparable to those in the sediments surrounding the artefacts, whereas used artefacts had many more starch grains, predominantly in the residues on their cutting edges. Barton et al. (1998) therefore considered it possible to distinguish starch deposits resulting from use of tools to cut or slice 
Ethnobotany Research \& Applications

starchy plant material from starch deposits resulting from contamination after the tool was discarded. Starch grains vary in size, shape and other morphological features. As with phytoliths, a particular type of starch grain may characterize a particular family, genus or, more rarely, a species, but not usually wild versus domesticated plants within the same species.

Loy et al. (1992) recovered starch grains, associated with calcium oxalate druses and raphides, from artefacts from a cave on Buka Island, in Melanesia. The grains were too small to have come from sago or many of the yams. Their shape, together with the presence and shape of the raphides, indicated also that they were not from cycad or sweet potato, but were typical of aroids. Residues identified as Colocasia were present on tools from the earliest occupation (c. 28,700-20,100 BP) onwards. Loy et al. (1992) claimed this as evidence that wild taro was more widely distributed than previously thought, but it could also support Spriggs' (1996) contention that Melanesians have been transporting and transplanting useful plants between islands for many millennia.

Like the macroscopic record, the microscopic record is as yet too incomplete to offer more than tantalizing hints of the picture that may result when Pacific archaeologists more routinely examine stone tools for starch residues, recover phytoliths from sediments, and take cores for pollen analysis from potential field as well as settlement sites. Taken together, the macroscopic and microscopic remains make a plausible case for considerable reliance on fruit and nut trees, supplemented by taro and/or other aroids, at least by Lapita times, together with some manipulation of these species in the form of intentional planting on cleared land and dispersal between islands. How far this manipulation proceeded in the direction of domestication (i.e. whether or what genetic changes became fixed in populations associated with man), whether domestication is always a significant or necessary stage in the origin of agriculture (Spriggs, 1996), and to what extent arboriculture (Kirch, 1989) can be considered agriculture (which in the literal sense is cultivation of fields), will no doubt remain subjects for debate. However, molecular studies on living crops may provide evidence that the archaeobotanical record cannot on whether manipulation of the tree crops important to the Lapita, and domestication of other crops such as bananas, sugarcane, taro and yam, started in Melanesia (Gosden, 1992; Yen 1995) or further west in South-east Asia (Bellwood, 1996), hence closer to the site of Sauer's original hearth (Sauer, 1952).

\section{Molecular data}

Molecular techniques which have been used to investigate the origins of crops include molecular cytogenetics, DNA fingerprinting and DNA sequencing. To date, these have been applied to relatively few Pacific crops but studies in other parts of the world show their potential for addressing unresolved questions in Pacific archaeo- and ethnobotany.

\section{Molecular cytogenetics}

DNA in chromosomes in conventional mitotic spreads can be denatured in situ on the microscope slide, then probed with DNA labeled with a fluorochrome. The probe DNA binds to homologous segments of the denatured chromosomal DNA, while the fluorochrome enables these sites to be seen when the preparation is viewed under light of an appropriate wavelength. Different probes, labelled with different fluorochromes, may be applied to the same cell, causing different parts of the chromosome complement to fluoresce in different colors. These techniques are therefore known as chromosome painting or fluorescent in situ hybridisation (FISH). Genomic in situ hybridisation (GISH) is a type of FISH in which the total genomic DNA of a given species is used as the probe. GISH has proved particularly valuable in the study of polyploids.

For example, D'Hont et al. (2000) used GISH to demonstrate that two sets of chromosomes from Musa acuminata (genomic formula $\mathrm{AA}$ ) and one set from M. balbisiana (BB) are present, as expected, in triploid bananas of the $A A B$ genome group (which includes the Pacific plantains). D'Hont et al. (2000) also showed that the S genome from M. schizocarpa, a wild species endemic to New Guinea, and the T genome from an unidentified species in section Australimusa occur in at least one diploid and one triploid clone respectively. These AS and AAT bananas must have originated through hybridizations independent of the cross(es) which gave rise to the $A B, A A B$ and $A B B$ bananas. When more clones have been surveyed and the distributions of the $S$ and $T$ genomes in bananas from New Guinea and the Western Pacific are better known, we should be able to trace more precisely the origins and dispersals of these subsets of domesticated bananas.

The elegant work on sugarcane reported by Grivet et al. (2004) shows that GISH can be used successfully on species with large numbers of small chromosomes. It may thus be possible to use GISH to investigate the origins of such Pacific cultigens as yam (Dioscorea alata, $2 n=3 x$ $-8 \mathrm{x}=30-80$ ) and kava (Piper methysticum, $2 \mathrm{n}=10 \mathrm{x}=$ $130)$, as well as to resolve the much-debated question of the ancestry of the sweet potato $(2 n=6 x=90)$. 


\section{Pickersgill - Crops and Cultures in the Pacific: New Data and New Techniques for the Investigation of Old Questions}

\section{DNA fingerprinting}

The techniques available for studying DNA polymorphisms are continually increasing. Most have in common the use of primers to amplify particular segments of DNA in the sample under study. These segments are separated by gel electrophoresis and fragments of different sizes then revealed by staining. Each primer generates a number of bands and the pattern of bands may be compared between individuals, populations or species. Some bands will be present in all samples (monomorphic); others will be present in some but absent in others (polymorphic). If a sufficiently large number of primers is used, individuals with different genotypes can be distinguished by their different banding patterns. These techniques are therefore collectively known as DNA fingerprinting techniques. Those used most frequently in studying the origins and dispersals of crops are RAPDs (randomly amplified polymorphic DNA), AFLPs (amplified fragment length polymorphisms), SSRs (simple sequence repeats, also known as microsatellites) and ISSRs (inter-simple sequence repeats).

These studies have generally demonstrated that domesticates are less variable than their wild progenitors, i.e. there is a founder effect or genetic bottleneck associated with domestication. Spread of crops by man from one continent to another may be associated with further bottlenecks and further restrictions in the diversity present in the new area. For example, in tomato, genetic diversity is greatest in wild tomatoes, which possess some alleles not present in domesticated tomatoes (the expected bottleneck associated with domestication). Cultivars released in or before the 1960s contain an even smaller sample of diversity, presumably reflecting further bottlenecks associated with spread of this crop from Mexico to Europe and from Europe back to North America (Williams and St. Clair, 1993).

The spread of tomatoes by man from Mexico to Europe is relatively recent. Crops that underwent long-distance dispersals earlier in their history may have evolved new characters in the original area, the new area, or both. For example, authorities disagree about whether Mesoamerican "wild" cacao (Theobroma cacao) is the immediate progenitor or a feral derivative of Mesoamerican cultivated cacao. Whitkus et al. (1998) analysed RAPD banding patterns and found that specimens of Mexican wild cacao group separately from all other cacao, while Mesoamerican cultivated cacao is more similar to South American cacao than to Mexican wild cacao. These data support the view that wild cacao reached Mesoamerica early, by natural dispersal, but that cacao introduced later by man, from South America, was the source of Mesoamerican cultivated cacao.

Sometimes DNA fingerprinting techniques can pinpoint the place of domestication of a crop quite precisely. AFLP studies of einkorn wheat (Triticum monococcum) showed that wild einkorn from south-east Turkey differs from wild einkorn from other parts of the Fertile Crescent, and that domesticated einkorn is more closely related to wild einkorn from south-east Turkey than to other wild einkorns. Archaeobotanical remains from sites in south-east Turkey include some of the earliest specimens of domesticated einkorn. Molecular and archaeobotanical investigations therefore agree in locating the probable site of domestication of einkorn wheat in south-east Turkey (Heun et al., 1997).

Similar studies, but using SSRs not AFLPs, have shown that domesticated cassava (Manihot esculenta) groups with wild cassava from southern Amazonia, not northern Amazonia or eastern Brazil (Olsen and Schaal, 2001). Olsen and Schaal (2001) concluded that their data support a single center of domestication, not multiple centres in different parts of the range of wild cassava, and origin from a single species, without the interspecific introgression suggested by Rogers (1965).

Kagy and Carreel (2004) have shown the potential of molecular studies for investigating possible center(s) of origin, routes of dispersal and subsequent diversification of Pacific cooking bananas. DNA fingerprinting studies on other crops putatively linked with early arboriculture or agriculture in the Pacific could therefore produce fascinating information on bottlenecks associated with successive eastward dispersals (natural or man-assisted) of these species to distant island groups, as well as on possible locations of the populations that served as sources for these dispersals.

\section{DNA sequencing}

DNA fingerprinting techniques sample many regions across the entire genome, but the data cannot be analyzed cladistically. DNA sequence data, on the other hand, are usually obtained from a small, hence potentially unrepresentative, portion of the genome but can be analyzed phylogenetically in various ways. DNA sequencing may therefore sometimes reveal events in the origins and dispersals of crops that could not be deduced from DNA fingerprinting.

Chacón (2001) sequenced non-coding regions from various parts of the chloroplast genome of wild and domesticated common bean (Phaseolus vulgaris) and found 13 different haplotypes in wild beans. Only 4 of these haplotypes occur also in domesticated beans (another example of founder effect associated with domestication). Mesoamerican wild and domesticated beans share three different haplotypes. This may represent a single domestication from a polymorphic wild population, followed by lineage sorting, or, alternatively, multiple domestications of common bean in Mesoamerica. Andean domesticated beans carry a different haplotype, which in wild beans is 
Ethnobotany Research \& Applications

restricted to South America. Beans must therefore have been domesticated in South America independently of their domestication(s) in Mesoamerica, as previously concluded from other data, including DNA fingerprinting data (Becerra Velásquez and Gepts, 1994; Sonnante et al., 1994).

Chacón then constructed a network linking the 13 haplotypes of wild beans by single mutational steps and analyzed the geographic distributions of the various branches in this network by the method pioneered by Templeton and his co-workers (Templeton et al., 1995; Templeton, 1998). Chacón inferred three long-distance (intercontinental) dispersal events, one early and two later in the history of wild beans. Since seeds of wild beans are not obviously adapted to long-distance dispersal by natural vectors such as wind or birds, it is possible that man may have spread this species long before he domesticated it. Certainly man still exploits both green pods and seeds of wild beans (Beebe et al., 1997). There are obvious parallels here for the study of some of the species exploited by man in the Pacific.

Recently, attempts have been made to infer from sequence data the size as well as the identity and location of the founder population from which a domesticate developed. The closest wild relative of maize is teosinte. Sequences have been obtained from maize and teosinte for three genes. Two appear to be selectively neutral, and code for a seed protein (Hilton and Gaut, 1998) and an enzyme (Eyre-Walker et al., 1998) respectively. The third controls a major difference between maize and teosinte (tb-1; Wang et al., 1999), hence was presumably subject to strong human selection during domestication. The part of tb-1 sequenced included the transcriptional unit and an upstream non-transcribed region presumed to contain the regulatory sequences responsible for the morphological effects of tb-1. For the two selectively neutral genes, and the transcriptional unit of tb-1, the gene phylogenies showed maize and teosinte sequences to be thoroughly intermixed, occurring together in several different clades. This was attributed to the same lineage sorting effect suggested for beans. But for the non-transcribed region of tb1 , all the maize sequences occur in a single clade, more closely associated with Balsas teosinte (Zea mays ssp. parviglumis) than with any other subspecies or species of teosinte. This was interpreted as indicating strong effects of human selection on the region of tb-1 concerned with development of the characteristic ear of maize, and also that Balsas teosinte, not the other teosintes, was the progenitor of maize. Hilton and Gaut (1998) and Eyre-Walker et al. (1998) then attempted to calculate the size of the population domesticated to produce maize. The calculations involved some assumptions that the authors recognized might not be fully justified, and were hampered by a lack of archaeological information on the time required to convert teosinte to maize. However, both groups concluded that the founding population was unlikely to have exceeded $3000-5000$ individuals, or about $6 \%$ of the total population of the wild progenitor (Eyre-Walker et al. (1998).

Sequencing studies are still expensive, but the phylogenetic analyses that they permit enable questions about the origins and dispersals of crops to be investigated more precisely and more rigorously than is possible with the cheaper fingerprinting techniques. Sequencing of human DNA promises to improve our understanding of the peopling of the Pacific (Hagelberg et al., 1994, Oppenheimer and Richards, 2001). Phylogeographic studies of the places of origin and routes of dispersal of the plant species important to those people would complete our picture of one of our species' significant achievements: the discovery and prolonged occupation of some of the most isolated islands in the world.

\section{Conclusions}

Although much more is known about agricultural origins and dispersals in South-east Asia and the Pacific than when Sauer (1952) wrote his synthesis, the information available has fueled new controversies rather than settled old arguments. There is a persuasive body of evidence that Melanesia was a center of independent domestication of plants, but we do not yet know how old this center is, nor whether it was additional or alternative to a Southeast Asian center.

The archaeobotanical record from the Pacific region was virtually non-existent 50 years ago. It is now steadily increasing, but its interpretation is hampered by a shortage of morphological markers of domestication in the archaeobotanical specimens of the tree fruits and nuts and the root and tuber crops so important in this region. Molecular studies on living collections of some of the critical species could contribute much to a better understanding of the interactions between man and plants throughout the Pacific. Studies on isozyme polymorphisms (Lebot and Aradhya, 1991; Lebot et al., 1993) demonstrate the possibilities of such studies but are handicapped by the relatively limited polymorphism in isozymes compared to DNA. Moreover isozymes have to be extracted and analyzed as soon as possible after the living source material has been collected. This requires appropriately equipped laboratories in the regions of interest. DNA studies also require laboratories and equipment not yet widely available in the tropics, but DNA, unlike isozymes, can be extracted from silica-gel dried material and studied half a world away from the site of collection. Collaboration between research laboratories in developed countries and ethnobotanists in the field would significantly improve our understanding of the origins and dispersals of crops and cultures in the Pacific and thereby build one more bridge with traditional knowledge. 


\section{Pickersgill - Crops and Cultures in the Pacific: New Data and New Techniques for the Investigation of Old Questions}

\section{Literature cited}

Athens, J.S., J.V. Ward \& G.M. Murakami. 1996. Development of an agroforest on a Micronesian high island: prehistoric Kosraean agriculture. Antiquity 70:834-846.

Barton, H., R. Torrence \& R. Fullagar. 1998. Clues to stone tool function re-examined: comparing starch grain frequencies on used and unused obsidian artefacts. Journal of Archaeological Science 25:1231-1238.

Bayliss-Smith, T. 1996. People-plant interactions in the New Guinea highlands: agricultural hearthland or horticultural backwater? Pages 499-523 in D.R. Harris, ed., The origins and spread of agriculture and pastoralism in Eurasia. UCL Press, London.

Becerra Velásquez, V.L. \& P. Gepts. 1994. RFLP diversity of common bean (Phaseolus vulgaris) in its centres of origin. Genome 37:256-263.

Beebe, S., O. Toro Ch., A.V. González, M.I. Chacón \& D.G. Debouck. 1997. Wild-weed-crop complexes of common bean (Phaseolus vulgaris L., Fabaceae) in the Andes of Peru and Colombia, and their implications for conservation and breeding. Genetic Resources and Crop Evolution 44:73-91.

Bellwood, P. 1996. The origins and spread of agriculture in the Indo-Pacific region: gradualism and diffusion or revolution and colonisation? Pages 465-498 in D.R. Harris, ed., The origins and spread of agriculture and pastoralism in Eurasia. UCL Press, London.

Chacón, S., M.I. 2001. Chloroplast DNA polymorphisms and the evolution and domestication of the common bean (Phaseolus vulgaris L.). Ph.D. thesis, The University of Reading, U.K.

D'Hont, A., A. Paget-Goy, J. Escoute \& F. Carreel. 2000. The interspecific genome structure of cultivated banana, Musa spp., revealed by genomic in situ hybridisation. Theoretical and Applied Genetics 100:177-183.

Eyre-Walker, A., R.L. Gaut, H. Hilton, D.L. Feldman \& B.S. Gaut. 1998. Investigation of the bottleneck leading to the domestication of maize. Proceedings of the National Academy of Sciences of the USA 95: 4441-4446.

Gosden, C. 1992. Production systems and the colonisation of the Western Pacific. World Archaeology 24: 55-69.

Grivet, L., C. Daniels, J.C. Glaszmann \& A. D'Hont. 2004. A review of recent molecular genetics evidence for sugarcane evolution and domestication. Ethnobotany Research and Applications 2:9-17.
Hagelberg, E., S. Quevedo, D. Turron \& J.B. Clegg. 1994. DNA from ancient Easter Islanders. Nature 369: 25-26.

Harries, H., L. Baudouin \& R. Cardeña. 2004. Floating, boating and introgression: molecular techniques and the ancestry of coconut palm populations on Pacific islands. Ethnobotany Research and Applications 2:37-53.

Hather, J. \& P.V. Kirch. 1991. Prehistoric sweet potato (Ipomoea batatas) from Mangaia Island, Central Polynesia. Antiquity 65: 887-893.

Hayward, D.M. \& D.W. Parry. 1980. Scanning electron microscopy of silica deposits in the culms, floral bracts and awns of barley (Hordeum sativum Jess.). Annals of Botany 46: 541-548.

Heun, M., R. Schäfer-Pregl, D. Klawan, R. Castagna, M. Acerbi, B. Borghi \& F. Salamini. 1997. Site of einkorn wheat domestication identified by DNA fingerprinting. Science 278: 1312-1314.

Hilton, H. \& B.S. Gaut. 1998. Speciation and domestication in maize and its wild relatives: evidence from the globulin-1 gene. Genetics 150: 863-872.

Kagy, V. \& F. Carreel. 2004. Bananas in New Caledonian Kanak society: their socio-cultural value in relation with their origins. Ethnobotany Research and Applications 2: 29-36.

Kealhofer, L. \& D.R. Piperno. 1994. Early agriculture in southeast Asia: phytolith evidence from the Bang Pakong Valley, Thailand. Antiquity 68: 564-572.

Kelly, E.F., R.G. Amundson, B.D. Marino \& M.J. Deniro. 1991. Stable isotope ratios of carbon in phytoliths as a quantitative method of monitoring vegetation and climate change. Quaternary Research 35: 222-233.

Kirch, P.V. 1989. Second millennium B.C. arboriculture in Melanesia: archaeological evidence from the Mussau Islands. Economic Botany 43: 225-240.

Lebot, V. \& K.M. Aradhya. 1991. Isozyme variation in taro (Colocasia esculenta (L.) Schott.) from Asia and Oceania. Euphytica 56: 55-66.

Lebot, V., K.M. Aradhya, R. Manshardt \& B. Meilleur. 1993. Genetic relationships among cultivated bananas and plantains from Asia and the Pacific. Euphytica 67: 163-175.

Loy, T.H., M. Spriggs \& S. Wickler. 1992. Direct evidence for human use of plants 28,000 years ago: starch residues on stone artefacts from the northern Solomon Islands. Antiquity 66: 898-912. 
Mangelsdorf, P.C. 1953. Review of "Agricultural origins and dispersals", by Carl O. Sauer. American Antiquity 19: 86-90.

Matthews, P.J. \& C. Gosden. 1997. Plant remains from waterlogged sites in the Arawe Islands, West New Britain Province, Papua New Guinea: implications for the history of plant use and domestication. Economic Botany 51: 121-133.

Olsen, K.M. \& B.A. Schaal. 2001. Microsatellite variation in cassava (Manihot esculenta, Euphorbiaceae) and its wild relatives: further evidence for a southern Amazonian origin of domestication. American Journal of Botany 88: 131-142.

Oppenheimer, S.J. and M. Richards. 2001. Slow boat to Melanesia? Nature 410: 166-167.

Rogers, D.J. 1965. Some botanical and ethnological considerations of Manihot esculenta. Economic Botany 19: 369-377.

Sauer, C.O. 1952. Agricultural origins and dispersals. American Geographical Society, New York.

Sonnante, G., T. Stockton, R.O. Nodari, V.L. Becerra Velásquez \& P. Gepts. 1994. Evolution of genetic diversity during the domestication of common bean (Phaseolus vulgaris). Theoretical and Applied Genetics 89: 629-635.

Spriggs, M. 1996. Early agriculture and what went before in Island Melanesia: continuity or intrusion? Pages 524537 in D.R. Harris, ed., The origins and spread of agriculture and pastoralism in Eurasia. UCL Press, London.

Templeton, A.R. 1998. Nested clade analyses of phylogeographic data: testing hypotheses about gene flow and population history. Molecular Ecology 7:381-397.

Templeton, A.R., E. Routman \& C.A. Phillips. 1995. Separating population structure from population history: a cladistic analysis of the geographical distribution of mitochondrial DNA haplotypes in the tiger salamander, Ambystoma tigrinum. Genetics 140:767-782.

Wang, R.-L., A. Stec, J. Hey, L. Lukens \& J. Doebley. 1999. The limits of selection during maize domestication. Nature 398:236-239.

Whitkus, R., M. de la Cruz, L. Mota-Bravo \& A. GómezPompa. 1998. Genetic diversity and relationships of cacao (Theobroma cacao L.) in southern Mexico. Theoretical and Applied Genetics 96:621-627.

Williams, C.E. \& D.A. St. Clair. 1993. Phenetic relationships and levels of variability detected by restriction fragment length polymorphism and random amplified poly- morphic DNA analysis of cultivated and wild accessions of Lycopersicon esculentum. Genome 36:619-630.

Yen, D.E. 1995. The development of Sahul agriculture with Australia as bystander. Antiquity 69:831-847. 